\title{
Apoptosis induced by novel aldehyde calpain inhibitors in human tumor cell lines
}

\author{
NA GUAN ${ }^{1}$, RAJANI KORUKONDA $^{2}$, EUNJU HURH ${ }^{1}$, THOMAS D. SCHMITTGEN ${ }^{1}$, \\ ISAAC O. DONKOR $^{2}$ and JAMES T. DALTON ${ }^{1}$ \\ ${ }^{1}$ Division of Pharmaceutics, College of Pharmacy, The Ohio State University, Columbus, OH; \\ ${ }^{2}$ Department of Pharmaceutical Sciences, College of Pharmacy, University of Tennessee, Memphis, TN, USA
}

Received March 18, 2006; Accepted May 17, 2006

\begin{abstract}
Calpain is a class of $\mathrm{Ca}^{2+}$-dependent cysteine proteases and has been suggested to be involved in several important signaling cascades. A series of novel aldehyde calpain inhibitors identified in our laboratory were more potent and specific than commercially available calpain inhibitors, and were used to assess the involvement of calpain in cancer. Our inhibitors demonstrated potent anti-proliferative activity in four cancer cell lines (PC-3, HeLa, Jurkat and Daudi) with $\mathrm{IC}_{50}$ 's ranging from 2 to $>30 \mu \mathrm{M}$. A non-cancer cell line $(\mathrm{CV}-1)$ was 4-7-fold less sensitive than the cancer cell lines. Apoptotic activity was determined and appeared to be inversely correlated to calpain expression levels in the different cell types. Leukemia cell lines (i.e., Daudi and Jurkat) with undetectable m-calpain were more susceptible to the apoptotic effects in response to calpain inhibition, while apoptosis was not detected in PC-3 prostate cancer cells, which highly express m-calpain. The extent of apoptosis in HeLa cells was moderate under identical conditions. Apoptosis induced by calpain inhibition was accompanied by caspase- 3 activation. Furthermore, cell cycle analysis showed that aldehyde calpain inhibitors arrested cells at the G2/M boundary in a concentration-dependent manner. These results indicate that aldehyde calpain inhibitors exhibit their cytotoxic effects via induction of $\mathrm{G} 2 / \mathrm{M}$ arrest and apoptosis. Importantly, the compounds failed to exert any inhibitory effects toward $20 \mathrm{~S}$ proteasome. Collectively, our results suggest that calpain is a novel target for the treatment of a variety of cancer diseases and provide leads for further discovery and development of calpain inhibitors.
\end{abstract}

Correspondence to: Dr James T. Dalton, Division of Pharmaceutics, College of Pharmacy, The Ohio State University, 500 West 12th Avenue, Columbus, OH 43210, USA

E-mail: dalton.1@osu.edu

Abbreviations: PS, phosphatidylserine

Key words: calpain, apoptosis, cell cycle

\section{Introduction}

Appropriate, controlled proteolysis is essential for cell functions including protein catabolism, protein processing, and homeostasis. Many diseases, including cancer, are derived from the deficiency or upregulated function/expression of certain functional proteins, which are substrates of various proteolytic enzymes. Hence, it is possible to influence a cascade of signal transduction events by regulating the activity of a single proteolytic enzyme (1-3). For example, proteases have recently drawn much attention as targets for anticancer drug design. PS-341, a novel proteasome inhibitor has been successfully used in clinical anticancer treatment $(2,3)$.

Calpain is a class of neutral $\mathrm{Ca}^{2+}$-activated non-lysosomal cysteine proteases with two major ubiquitously expressed isoforms known as $\mu$-calpain (or calpain I) and m-calpain (or calpain II) based on their $\mathrm{Ca}^{2+}$ requirement for activation in vitro with $\mu$-calpain requiring a micromolar concentration of $\mathrm{Ca}^{2+}$ and $\mathrm{m}$-calpain requiring a millimolar concentration of $\mathrm{Ca}^{2+}$. Calpain has a large number of intracellular protein substrates that were identified in vitro including kinases (4) and phosphatases (5), proto-oncogenes $(6,7)$, cytoskeletal proteins $(8,9)$ and some transcription factors including c-Jun (10) and IкB (11). These protein substrates play very important roles in cell proliferation, apoptosis, cell cycle control and cell migration. Calpain has attracted a lot of attention due to the role it plays in the modulation of various aspects of cell physiology, including apoptosis (12-15), cell migration $(16,17)$ and cell proliferation $(18,19)$. $\beta$-cat ${ }^{75}$, a calpain-mediated $\beta$-catenin cleavage product, is more stable than wild-type $\beta$-catenin and may increase tumorigenic potential in prostate and breast cancer cells (20). Recent studies showed that mcalpain expression is enhanced in metastatic prostate cancer specimens (20) and in colorectal adenocarcinomas (21) as compared to normal tissue. Moreover, there is considerable evidence that inhibition of calpain suppresses cell growth and promotes apoptosis in a variety of human cancer cell lines $(12-15,22)$. Thus, calpain could offer a novel target for anticancer treatment through induction of active cell death, arresting cell growth and tumor invasiveness.

To date, calpain inhibitors I and II have been used widely to trigger apoptosis in various cancer cell lines. However, these inhibitors are not specific to calpain because they inhibit 
lysosomal enzymes such as $20 \mathrm{~S}$ proteasome (23). Thus, it is difficult to deduce the causal role of calpain inhibition in apoptosis. We previously reported a series of peptidyl aldehydes that potently and selectively inhibited $\mu$-calpain (24). We extended these findings in the current study to explore the ability of these compounds to inhibit tumor cell growth and induce apoptosis as a function of calpain expression and inhibition. The results of these studies are reported herein. Our studies suggest that calpain is an attractive target for anticancer drug discovery and that those aldehyde analogs represent a promising pharmacophore for further modification.

\section{Materials and methods}

Cell culture. The human cell lines PC-3 (prostate cancer) and HeLa (cervical cancer) were obtained from American Type Culture Collection (Manassas, VA). The human cell lines Jurkat (T cell leukemia) and Daudi (Burkitt's lymphoma) were a kind gift from Dr Fatih M. Uckun (Drug Discovery Program, Wayne Hughes Institute). Cell lines were cultured in RPMI-1640 medium (Gibco, Grand Island, NY) supplemented with $2 \mathrm{mM}$ L-glutamine containing $10 \%$ (v/v) heat-inactivated fetal bovine serum (FBS) for leukemia cells and 10\% (v/v) FBS for HeLa, PC-3 and CV-1 cells, respectively. Cell cultures were maintained at $37^{\circ} \mathrm{C}$ in a humidified atmosphere containing $5 \% \mathrm{CO}_{2}$.

Preparation of aldehyde analogs. The syntheses of this series of analogs were reported previously (24).

MTT reductase assay. Cells were distributed into 96-well plates at a density of 2,000-15,000 cells/well, and exposed to a range of drug concentrations $(1-100 \mu \mathrm{M})$ for $96 \mathrm{~h}$ at $37^{\circ} \mathrm{C}$ in a $5 \% \mathrm{CO}_{2}$ atmosphere. Wells to which no drug was added were used as negative controls. At the end of treatment, an aliquot $(25 \mu \mathrm{l})$ of MTT [3-(4,5-dimethyl-2-thiazolyl)-2,5diphenyl-2H-tetrazolium bromide] dye $(5 \mathrm{mg} / \mathrm{ml})$ was added to each well for the final 2- to 4-h incubation. The plates were then centrifuged at $300 \mathrm{x}$ g for $15 \mathrm{~min}$. The supernatant medium in each well was aspirated, and the formazan product was solubilized with $100 \mu 1$ DMSO. The absorbance (A) values of wells were determined at $595 \mathrm{~nm}$ using a MRX microplate reader (DYNEX Technologies, VA). Percentage cell survival was plotted against the drug concentration and the $\mathrm{IC}_{50}$, the concentration of drug required to reduce living cell number by $50 \%$ as compared to non-drug treated wells, was determined by non-linear regression analysis using WinNonlin (Pharsight Corporation, Mountain View, CA).

Real-time RT-PCR. Total cellular RNA was extracted by RNeasy mini kit (Qiagen, Inc., Valencia, CA) according to the manufacturer's protocol, and immediately converted to cDNA by reverse transcription using SuperScript ${ }^{\mathrm{TM}}$ II reverse transcriptase (Gibco BRL, Life Technologies Inc., Gaithersburg, MD) and random hexamers. The following primers were designed by Primer Express software (Applied Biosystems, Foster City, CA) and used for the real-time PCR analysis: for $\mu$-calpain, 5'-GGAGGACATGGAGATCA GGG-3' (forward), 5'-TCACGATCCATGTTCACC-3' (reverse); for m-calpain, 5'-AGGGCGGTGGAATGACAAC-3' (forward), 5'-GGCGGGAATAGTGCCTCAG -3' (reverse); for 18S rRNA, 5'-GTAACCCGTTGAACCCCATT-3' (forward), 5'-CCATCCAATCGGTAGTAGCG-3' (reverse). 18S rRNA was used to normalize the PCR products for differences in the amount of total cellular RNA obtained during extraction. Real-time quantitative PCR was performed using a PRISM ${ }^{\text {TM }}$ 7900HT sequence detection system (Applied Biosystems) and SYBR-Green detection. $\mathrm{C}_{\mathrm{T}}$, the PCR cycle number that crossed an arbitrarily placed signal threshold, was determined. Gene expression was evaluated using $2-{ }^{\Delta \Delta \mathrm{C}_{\mathrm{T}}}$ method, where $\Delta \Delta \mathrm{C}_{\mathrm{T}}$ represents $\left[\left(\mathrm{C}_{\mathrm{T} \text { gene }}-\mathrm{C}_{\mathrm{T} 18 \mathrm{~S} \text { rRNA }}\right)_{\mathrm{Cell}}\right.$ line $-\left(\mathrm{C}_{\mathrm{T} \text { gene }}-\mathrm{C}_{\mathrm{T} 18 \mathrm{~S}}\right.$ rRNA $)_{\text {HeLa cells }}$ ( 25).

Western blotting. Cell lysates were prepared by resuspending cell pellets in the extraction buffer [100 mM HEPES (pH 7.5), $10 \%$ sucrose (wt/vol), $0.5 \mathrm{mM}$ EDTA, $10 \mathrm{mM}$ DTT] and incubating in ice for $15 \mathrm{~min}$. Cells were centrifuged at $720 \mathrm{x} \mathrm{g}$ for $5 \mathrm{~min}$, and the supernatant fraction was frozen at $-80^{\circ} \mathrm{C}$ prior to use. Protein concentrations were determined using the BCA assay (Pierce, Rockford, IL). Equal amounts of protein were loaded and separated by SDS-PAGE (4-12\% gradient) and transferred to nitrocellulose membranes. Membranes were blocked with $5 \%$ dry milk and probed by the following antibodies: mouse anti- $\mu$-calpain monoclonal antibody (1:5000, Chemicon, San Diego, CA), rabbit anti-m-calpain polyclonal antibody (1:2500, Affinity Bioreagents, Golden, CO), and rabbit polyclonal $\beta$-actin (1:5000, Abcam, Cambridge, MA). Appropriate conjugated secondary antibodies: goat anti-mouse IgG-HRP (1:1000, Santa Cruz Biotechnology Inc., Santa Cruz, CA) and donkey anti-rabbit IgG-HRP (1:5000, Amersham, Arlington Heights, IL), were used prior to detection by chemiluminescence (Amersham). The relative intensity of calpain protein from Western blotting was obtained by densitometry, corrected with the $B$-actin loading control, and compared with that observed in HeLa cells.

Annexin V-FITC assays. The translocation of phosphatidylserine (PS) to the surface of apoptotic cells was determined with Annexin V-fluorescein isothiocyanate (FITC) (BD Pharmingen, San Diego, USA) according to the manufacturer's recommendation. Propidium iodide (PI) was added to discriminate apoptotic cells from necrotic cells. Briefly, exponentially growing cells were plated at $6 \times 10^{6}$ cells per plate and treated with the compounds of interest for the indicated periods at a wide range of concentrations. Cells were collected, washed with ice-cold phosphate-buffered saline (PBS), and resuspended in 1X binding buffer. Shortly prior to analysis, an aliquot of control and treated samples containing $1 \times 10^{5}$ cells were transferred and stained with FITCconjugated Annexin V (5 $\mu \mathrm{l})$ and PI (5 $\mu \mathrm{l})$ for $15 \mathrm{~min}$ in the dark. Samples were analyzed using a FACScalibur flow cytometer equipped with a 488-nm argon laser and CellQuest software (BD Biosciences, San Jose, CA).

DNA fragmentation assays. Fragmented DNA was isolated using a modification of the procedure of Herrmann et al (26). Briefly, exponentially growing cells were plated at $6 \times 10^{6}$ cells per plate and treated with the compounds at the indicated concentrations for $24 \mathrm{~h}$. After the end of the incubation period, 
cells were collected and lysed in lysis buffer (1\% Nonidet $\mathrm{P}-40,20 \mathrm{mM}$ EDTA, $50 \mathrm{mM}$ Tris- $\mathrm{HCl} \mathrm{pH}$ 7.5). After centrifugation, the supernatant was collected. The extraction was repeated and SDS (final concentration 1\%) was added to the combined supernatant. The supernatants were first treated with RNase A for $2 \mathrm{~h}$ at $37^{\circ} \mathrm{C}$, and then treated with Proteinase $\mathrm{K}$ for $6 \mathrm{~h}$ at $65^{\circ} \mathrm{C}$. DNA was precipitated by adding $0.1 \mathrm{Vol}$ of $3 \mathrm{M}$ sodium acetate and $2 \mathrm{Vol}$ of ethanol. The pellet obtained by centrifugation was washed with $70 \%$ ethanol and dissolved in $20 \mu \mathrm{l}$ of $100 \mathrm{mM}$ Tris- $\mathrm{HCl}$ and $10 \mathrm{mM}$ EDTA ( $\mathrm{pH} 8.0$ ). The amount of DNA was measured at $\mathrm{A}_{260 \mathrm{~nm}}$ value, and its purity was determined by the ratio of $\mathrm{A}_{260 \mathrm{~nm}:} \mathrm{A}_{280 \mathrm{~nm}}$. Equal amounts of DNA were loaded onto a $1.8 \%$ agarose gel using $40 \mathrm{mM}$ Tris-acetate and $2 \mathrm{mM}$ EDTA as running buffer, and electrophoresed for $1.5 \mathrm{~h}$ at $80 \mathrm{~V}$. DNA laddering was visualized and photographed under UV illumination by Kodak Image Station 440 CF (PerkinElmer, Inc., Boston, MA).

Caspase-3 activity assays. Activation of caspase-3 was measured using a commercially available caspase- 3 assay kit (BD Pharmingen) according to the manufacturer's protocol. Briefly, exponentially growing cells were plated at $6 \times 10^{6}$ cells per plate and treated with the compounds for the indicated periods at 15 - or $25-\mu \mathrm{M}$ concentrations. After treatment, cells were fixed and permeabilized with Cytofix/Cytoperm solution followed by washing with Perm/Wash buffer. The fixed cells were suspended in the Perm/Wash buffer containing phycoerythrin (PE)-conjugated anti-active caspase 3 antibody and incubated for $30 \mathrm{~min}$ at room temperature. Cells were washed once with Perm/Wash buffer, and then cells were analyzed for PE fluorescence using a FACScalibur flow cytometer equipped with a 488-nm argon laser and CellQuest software (BD Biosciences).

Cell cycle analysis. Exponentially growing cells were treated at indicated concentrations for $24 \mathrm{~h}$. At the end of the incubation period, cells were collected and washed twice with PBS. Cells were then fixed in pre-chilled $70 \%$ ethanol for $2 \mathrm{~h}$. After an additional washing step, cells were treated with RNase A (final concentration, $0.5 \mathrm{mg} / \mathrm{ml}$ ) at $37^{\circ} \mathrm{C}$ for $30 \mathrm{~min}$ and stained with PI. Analysis was performed using a FACScalibur flow cytometer equipped with a 488-nm argon laser and CellQuest software (BD Biosciences). The percent of cells in the G0/G1, $\mathrm{S}$ and $\mathrm{G} 2 / \mathrm{M}$ phases was determined using ModFit software (Verify Software, Topsham, ME).

Proteasome inhibition assay. Inhibition of the chymotryptic activity of the $20 \mathrm{~S}$ proteasome was measured in 96-well plates as previously described (27). Briefly, latent rabbit $20 \mathrm{~S}$ proteasome (Calbiochem, San Diego, CA) was added to the buffer system (25 mM HEPES, 0.5 mM EDTA, 0.03\% $\mathrm{SDS}$, and $5 \mu \mathrm{M}$ of a synthetic calpain inhibitor) to a final concentration of $0.9 \mathrm{nM}$ in a final volume of $180 \mu 1$. PS-341 served as a positive control. The reaction temperature was maintained at $37^{\circ} \mathrm{C}$ for $5 \mathrm{~min}$. The assay was initiated by addition of $20 \mu \mathrm{l}$ of $0.1 \mathrm{mM}$ Suc-Leu-Leu-Val-Tyr-AMC (LLVY-AMC) (Bachem Biochemica GmbH, Heidelberg, Germany) and the increase in fluorescence emission at $440 \mathrm{~nm}$ $(\lambda \mathrm{ex}=380 \mathrm{~nm})$ due to the cleavage of AMC from the peptide-
Table I. Structures, cytostatic/cytotoxic activity, and $\mu$ calpain inhibition of aldehyde calpain inhibitors.

\begin{tabular}{|c|c|c|c|c|c|c|c|}
\hline \multirow{2}{*}{ Compound } & \multirow{2}{*}{ Structure } & \multicolumn{5}{|c|}{$I C_{s 0}(\mu M)$} & \multirow{2}{*}{$K_{\mathrm{i}}(\mu \mathrm{M})$} \\
\hline & & Daudi & Jurkat & HeLa & PC-3 & CV-1 & \\
\hline 1 & & 2.2 & 3.2 & 4.4 & 5.2 & 20.0 & 0.07 \\
\hline 2 & & 4.1 & 4.0 & 3.6 & 6.1 & 29.8 & 0.25 \\
\hline 3 & & 9.1 & 10.3 & 17.9 & 16.8 & 28.2 & 0.54 \\
\hline & & 16.7 & 17.6 & 48.9 & 40.0 & 70.2 & 0.08 \\
\hline 5 & & 18.4 & 21.7 & 28.5 & 17.0 & 84.6 & 0.02 \\
\hline
\end{tabular}

substrate was monitored over 8 min using a SPECTRAmax Gemini fluorescence plate reader (Molecular Devices, Sunnyvale, CA).

\section{Results}

MTT assay. The overall (i.e., cytostatic and cytotoxic) anticancer drug effects of the aldehyde calpain inhibitors were investigated in PC-3, HeLa, Jurkat, and Daudi cells by the MTT assay. Table I summarizes the $\mathrm{IC}_{50}$ values (overall anticancer drug effects) against these four cancer cell lines and previous reported $\mathrm{Ki}$ values (inhibitory potency) for $\mu$-calpain (24). Comparison of the $\mathrm{IC}_{50}$ values showed that the compounds displayed similar potency across the four cancer cell lines. The $\mathrm{IC}_{50}$ values for compounds 1 and 2 were significantly lower in the cancer cell lines than those observed for other aldehyde calpain inhibitors. The compounds demonstrated selective cytostatic/cytotoxic activity, with $\mathrm{IC}_{50}$ values 4-7-fold higher in CV-1 cells than in the cancer cells suggesting that they preferentially affect malignant cells. Despite having comparable calpain inhibitory potency and structure, compound 4 was not as effective as compound 1 in terms of antiproliferative effect.

The sensitivities toward compound 1 among the four cancer cell lines were examined in further detail. Fig. 1 shows the concentration-dependent cytostatic/cytotoxic effects of compound 1 . $\mathrm{IC}_{50}$ values of compound 1 in Jurkat, Daudi, HeLa and PC-3 cells were approximately equal (i.e., range 2.2-5.2 $\mu \mathrm{M}$ ). However, a compound 1 concentration $>10 \mu \mathrm{M}$ completely inhibited Daudi, Jurkat and HeLa cell proliferation, but only decreased formazan production by $\sim 80 \%$ at a concentration $\leq 50 \mu \mathrm{M}$ in PC-3 cells. Complete inhibition of PC-3 cell proliferation by compound 1 was only achieved at the highest concentration $(100 \mu \mathrm{M})$. Similar effects were observed with the other compounds in PC-3 cells, suggesting that those cells were uniquely resistant to the effects of these calpain inhibitors (data not shown). 


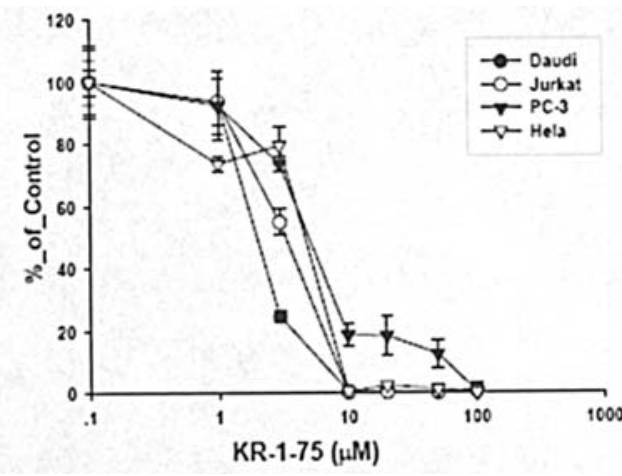

Figure 1. Cytotoxic/cytostatic effects of compound 1. Cells were treated with various concentrations of compound 1 for $96 \mathrm{~h}$. The MTT assay was performed after 96-h treatment, and cell viability was calculated as the percentage of untreated cells, as described in Materials and methods. Data represent the mean of six experiments. Error bars represent the SD.

A
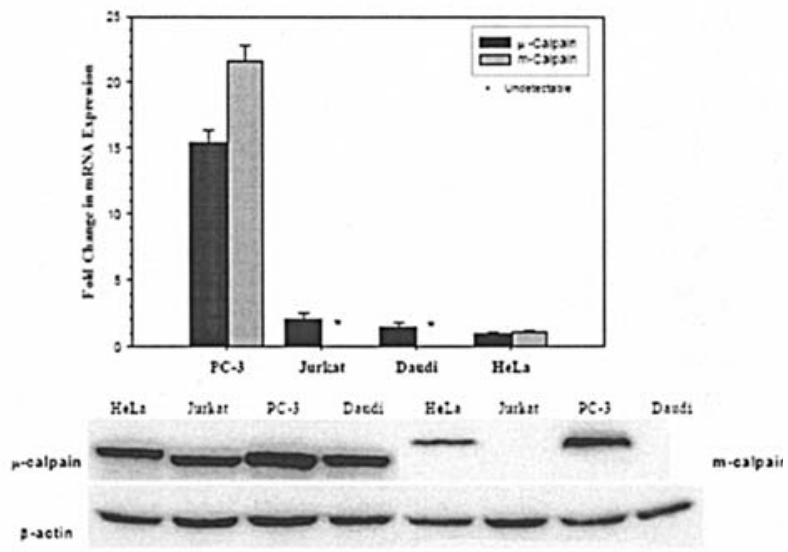

C

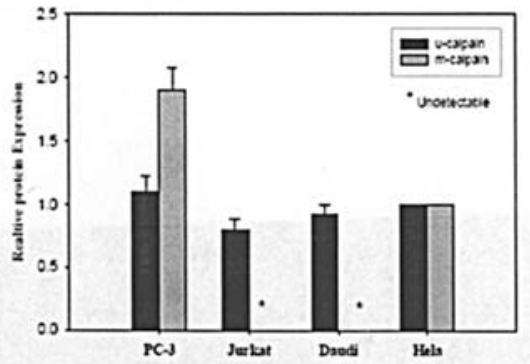

Figure 2. mRNA and protein expression of $\mu$ - and m-calpain in four cancer cell lines. A, mRNA expression of calpains determined by real-time RT-PCR. mRNA expression was normalized to $18 \mathrm{~S}$ rRNA, and compared to HeLa cells. Data are presented as the mean \pm SD of three experiments. Calpain protein expression was determined by Western blotting. B, representative blot from three independent experiments. C, quantitative values of densitometric analysis of Western blots normalized to $B$-actin loading control, and compared with HeLa cells. Data are presented with histograms as mean \pm $\mathrm{SD}(\mathrm{n}=3)$.

RT-PCR and Western blotting. We examined $\mu$-calpain and $\mathrm{m}$-calpain $\mathrm{mRNA}$ and protein expression in these four cancer cell lines in an attempt to further understand the observed difference in responses. Real-time RT-PCR was used to determine the gene expression of the calpain isoforms in each cell line normalized to $18 \mathrm{~S}$ rRNA and relative to the
$A$

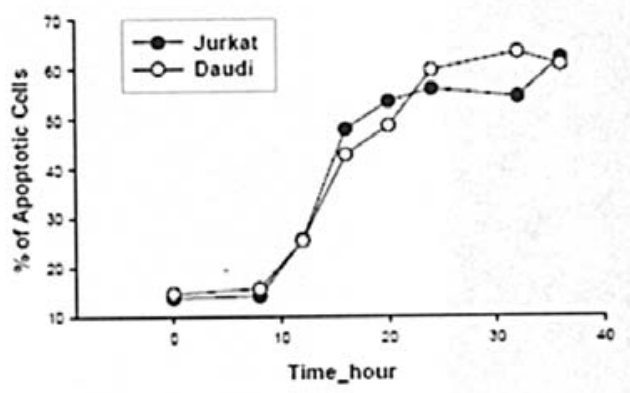

B

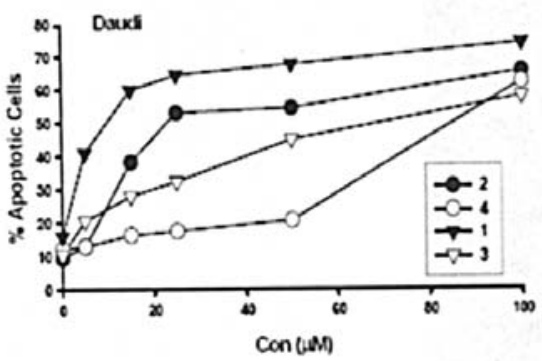

C

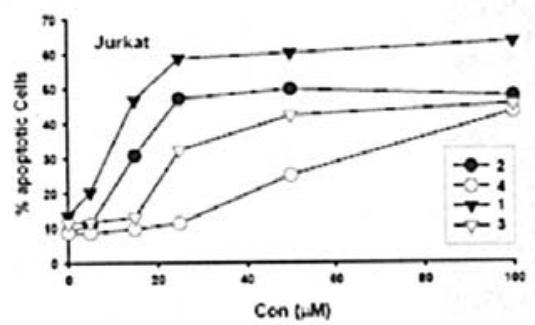

Figure 3. Calpain inhibitors-induced apoptosis. A, time-dependence of compound 1-induced apoptosis in leukemia cells. Leukemia cells were treated with $50 \mu \mathrm{M}$ compound 1 for the indicated duration. B, concentrationdependence of aldehyde calpain inhibitor-induced apoptosis in Daudi cells. $\mathrm{C}$, concentration-dependence of aldehyde calpain inhibitor-induced apoptosis in Jurkat cells. Jurkat and Daudi cells were treated with analogs at the indicated concentrations for $24 \mathrm{~h}$. The percentage of apoptotic cells at early and advanced apoptotic stages were quantified by Annexin V-FITC, as described in Materials and methods.

expression in HeLa cells. Fig. 2A shows $\mu$ - and m-calpain mRNA expression in the four cell lines. $\mu$-Calpain was constitutively expressed in all the cell lines tested. The mRNA expression level of $\mu$-calpain in PC-3 cells was 15 -fold higher than those in the other cell lines. In contrast, m-calpain mRNA expression in the two leukemia cell lines was below the limit of detection, and 20 -fold higher in PC-3 cells than in HeLa cells.

Protein expression of calpain in the four cell lines was analyzed by Western blotting and densitometric analysis (Fig. 2B and C). mRNA and protein expression of the calpains in these four cancer cell lines showed similar patterns. Levels of $\mu$-calpain protein expression were similar among the four cell lines, whereas m-calpain protein expression in Jurkat and Daudi cells was not detectable.

Apoptosis. The ability of the four aldehyde calpain inhibitors with a cyclic group at P2 (i.e., compounds 1-4) to trigger apoptosis of cancer cells was explored. We first used compound 1 to examine the time course for induction of apoptosis. Fig. 3A shows that compound 1-induced apoptosis increased with the duration of drug treatment in the leukemia cells, with 
A
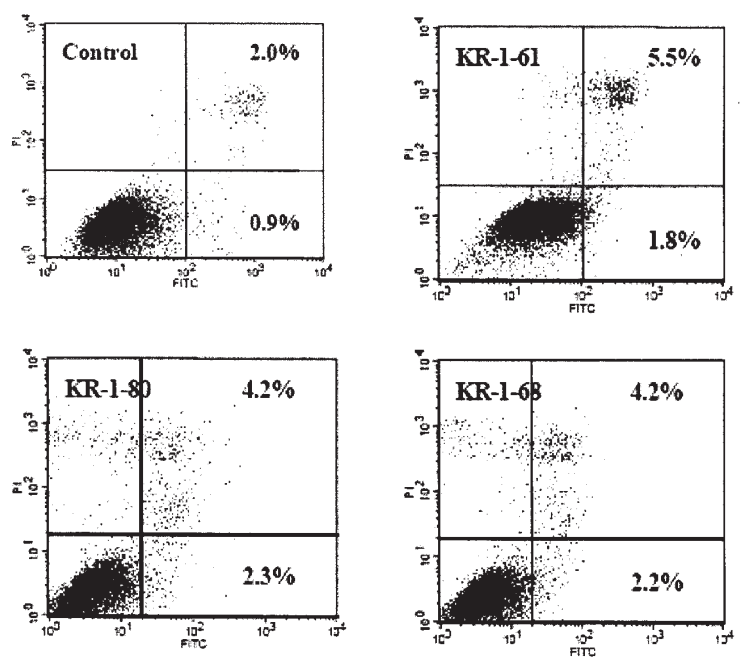

B

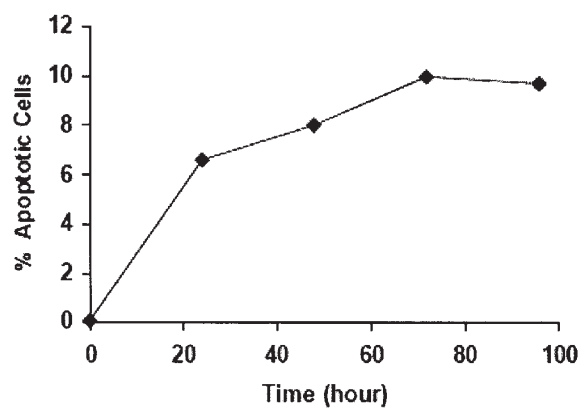

Figure 4. A, aldehyde calpain inhibitor-induced apoptosis in PC-3 cells. PC-3 cells were treated with aldehyde analogs at $100 \mu \mathrm{M}$ for $24 \mathrm{~h}$ and examined for apoptosis. B, time course for compound $1(50 \mu \mathrm{M})$-induced apoptosis in PC-3 cells. The early and advanced apoptotic stages were quantified by Annexin V-FITC, as described in Materials and methods.

minimal apoptosis observed at shorter exposure time (i.e., $\leq 8 \mathrm{~h}$ ). The percentage of apoptotic cells increased at $12 \mathrm{~h}$ and then plateaued at exposure times approaching or beyond
$24 \mathrm{~h}$, as assessed by Annexin V-FITC. Thus, 24-h incubation times were used in subsequent studies. Fig. 3B and $\mathrm{C}$ shows the apoptosis as a function of drug concentration in two leukemia cell lines measured by Annexin V-FITC. All four aldehyde analogs caused dose-dependent apoptosis with compound 4 demonstrating less activity than the other analogs. Compound 1 demonstrated the most potent and effective ability to induce apoptosis in the leukemia cell lines.

Fig. 4A shows the apoptosis induced by the aldehyde analogs in PC-3 cells. In general, the PC-3 cell line was less sensitive to calpain inhibition. Compounds 2, 3 and 4 induced marginal apoptosis $(<8 \%)$ in $\mathrm{PC}-3$ cells after treatment with a high concentration $(100 \mu \mathrm{M})$ for $24 \mathrm{~h}$. A similar extent of apoptosis was observed in PC-3 cells treated with compound 1 . The percentage of apoptotic cells increased with longer exposure to compound 1 (Fig. 4B), but never exceeded $10 \%$. Slightly greater apoptosis was observed in HeLa cells (data not shown), although the percentage of apoptotic cells was still significantly smaller (i.e., $<20 \%$ at the highest concentration) than that observed in leukemia cell lines.

We also determined whether compound 1 induced internucleosomal DNA fragmentation, the hallmark of apoptosis in these four cell lines (Fig. 5). Similar to our observations regarding to PS externalization, significant DNA fragmentation was observed after treatment of Daudi and Jurkat cells with compound 1, less DNA fragmentation was observed in HeLa cells, and no fragmentation was found in PC-3 (data not shown). As a whole, our cell proliferation and apoptosis data suggest that cytostasis rather than apoptosis is a dominant factor in PC-3 and HeLa cells in response to calpain inhibition.

To determine whether compound 1-induced apoptosis was accompanied by activation of caspase- 3 , an event that occurs in the early stages of apoptosis, activated caspase- 3 in the four cancer cells in response to 15 and $25 \mu \mathrm{M}$ compound 1 was detected by PE-conjugated anti-active caspase- 3 antibody. Fig. 6 shows that exposure of Jurkat, Daudi and HeLa cells to compound 1 activated caspase-3. Consistent with the results from PS externalization and DNA fragmentation studies, a relatively large percentage of caspase-3 activation was observed

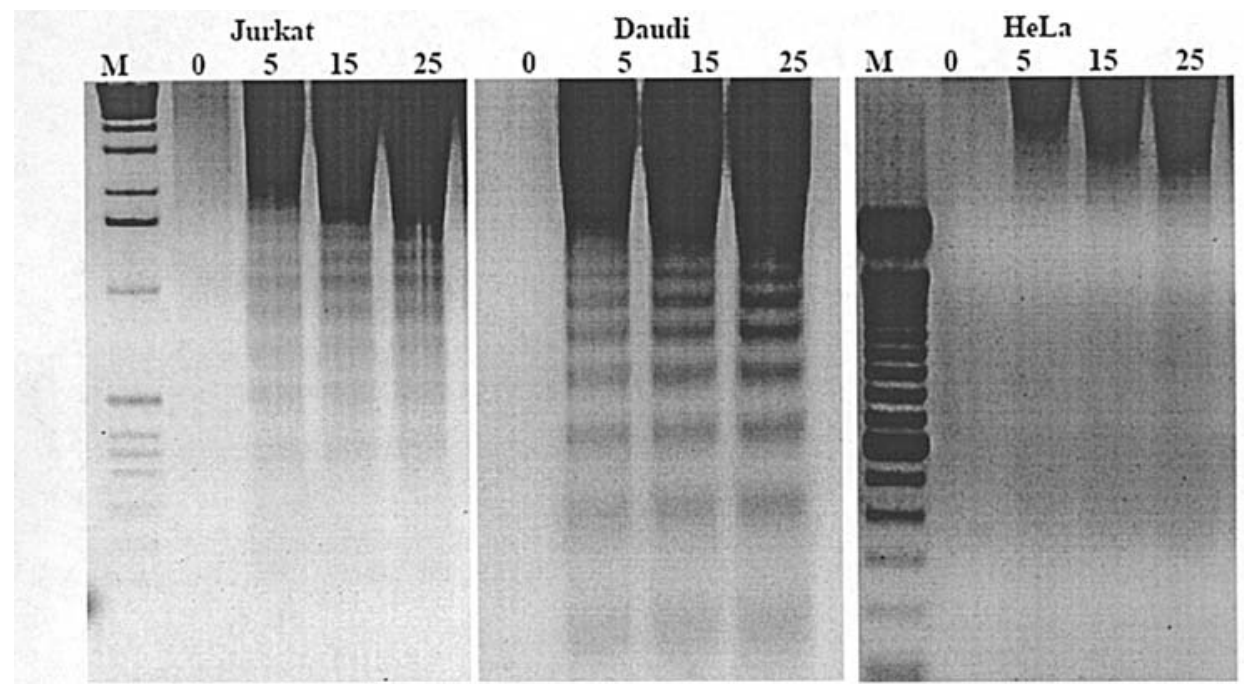

Figure 5. Concentration-dependent internucleosomal DNA cleavage induced by compound 1 in leukemia cells and HeLa cells. DNA was extracted from cancer cells after exposure to 5,15 , or $25 \mu \mathrm{M}$ of compound 1 for $24 \mathrm{~h}$. DNA was analyzed on a $1.8 \%$ agarose gel. M, 100-bp DNA size marker, 0, control. 

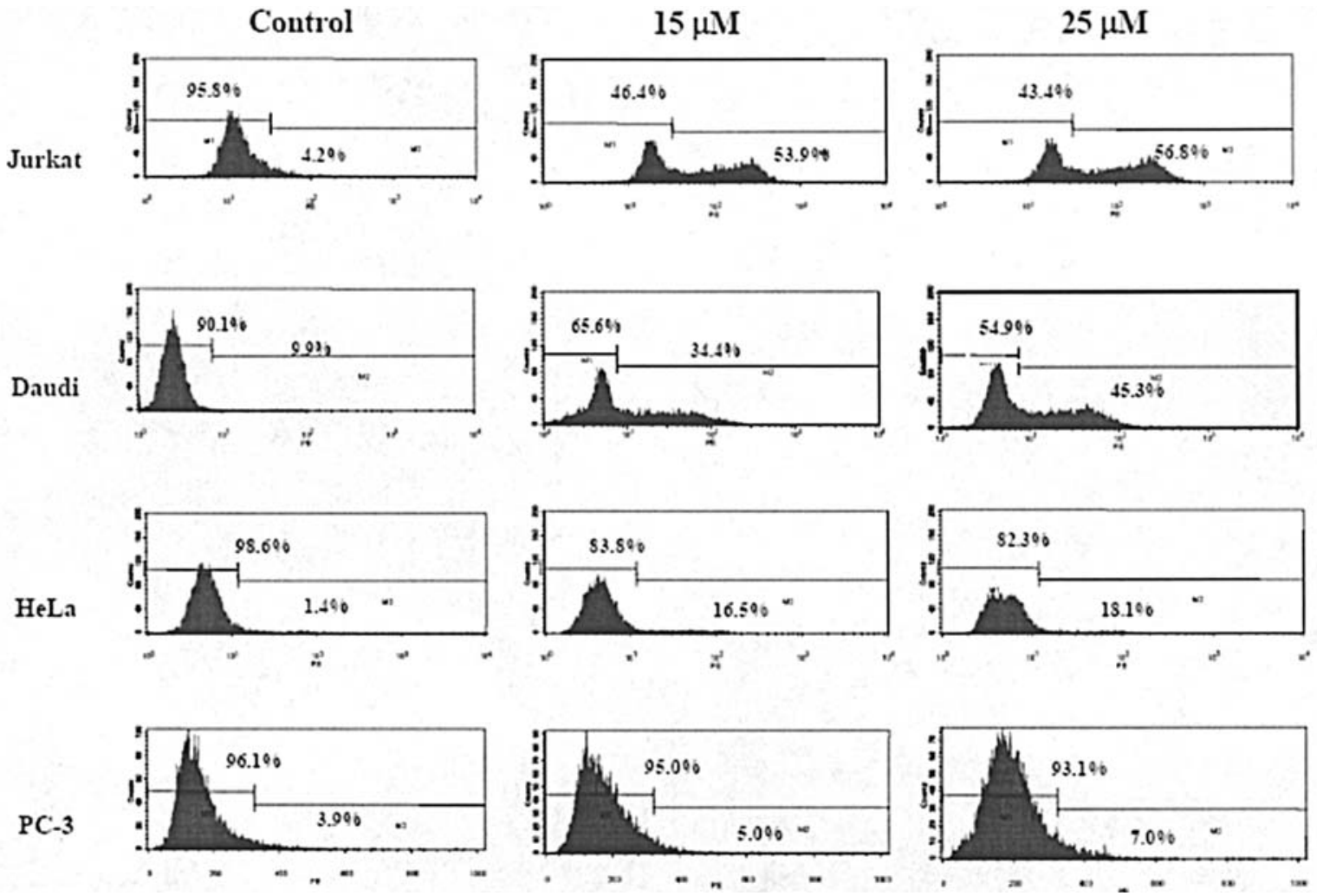

Figure 6. Activation of caspase-3 by compound 1 in cancer cells. Cancer cells were treated with compound 1 at the indicated concentrations for 24 h and stained with PE-conjugated anti-active caspase-3 antibody, as described in Materials and methods.
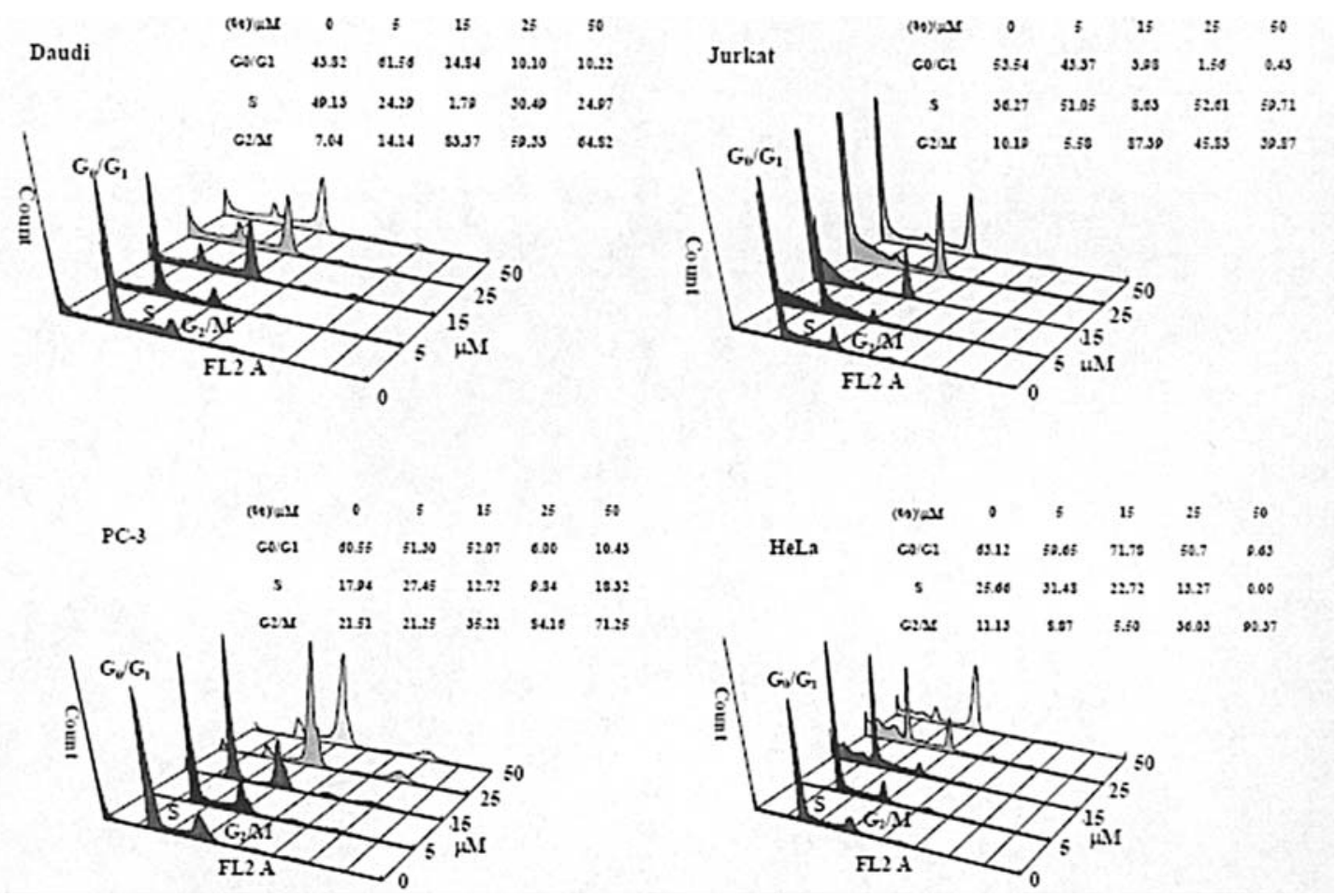

Figure 7. Compound 1 induced G2-M cell cycle arrest. Cell cycle analysis was performed by flow cytometry on the four cancer cell lines treated with compound 1 at the indicated concentrations for $24 \mathrm{~h}$. The results are depicted as a cascade plot. Inserts, \% cells in various stages of cell cycle.

in the presence of $25 \mu \mathrm{M}$ of compound 1 in leukemia cell lines $(57 \%$ in Jurkat and $45 \%$ in Daudi) followed by HeLa $(18 \%)$ and PC-3 (7\%).
Cell cycle recruitment in G2/M-phase of the cell cycle. The effect of compound 1 on the cell cycle of Jurkat, Daudi, PC-3 and HeLa was also examined after treatment with various 


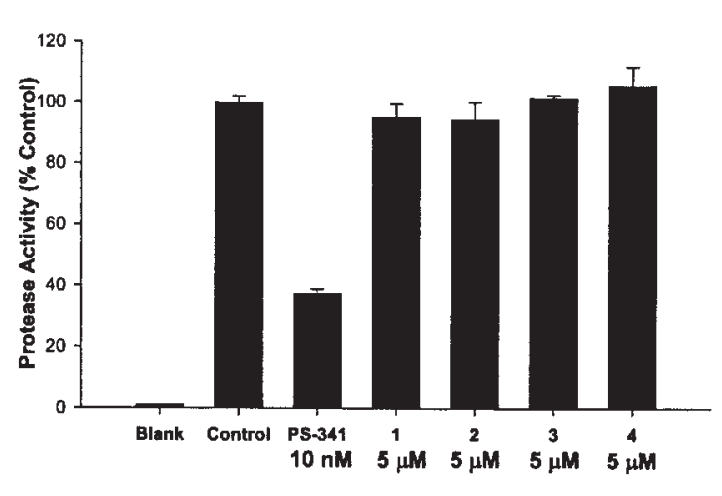

Figure 8 . Inhibition of $20 \mathrm{~S}$ proteasome by aldehyde calpain inhibitors and PS-341. Latent rabbit proteasome was incubated with SucLLVY-AMC in the presence of DMSO, $5 \mu \mathrm{M}$ of each aldehyde calpain inhibitor or $10 \mathrm{nM}$ PS-341. The cleavage of AMC was measured at $440 \mathrm{~nm}$ as described. All experiments were repeated three times. Columns, mean percentage of control; error bar, SD.

concentrations of the drug for $24 \mathrm{~h}$ using flow cytometric analysis of DNA content by PI staining. As shown in Fig. 7, compound 1 arrested cells at the G2/M boundary. G2-M phase arrest occurred in a concentration-dependent manner with $\leq 83 \%$ in Daudi, $87 \%$ in Jurkat, $84 \%$ in PC-3 and $90 \%$ in HeLa compared to $44 \%$ in Daudi, $54 \%$ in Jurkat, $61 \%$ in PC-3 and $63 \%$ in HeLa in the absence of compound 1. Moreover, the different cell lines showed different sensitivity to cell cycle perturbation. The maximal cell accumulations at $\mathrm{G} 2 / \mathrm{M}$ compartment in response to compound 1 occurred at $15 \mu \mathrm{M}$ in leukemia cells, $25 \mu \mathrm{M}$ in PC-3 and $50 \mu \mathrm{M}$ in HeLa, respectively. Prominent sub-G1 DNA peaks corresponding to the apoptotic population were only detected in leukemia cells.

Proteasome inhibition assay. The cross-reactivity of calpain inhibitor I and II with other proteolytic enzymes prompted us to examine the effects of our compounds on proteasome activity, a potential confounding variable in our studies (23). We examined SucLLVY-AMC degradation activity in latent rabbit $20 \mathrm{~S}$ proteasome in the presence of our aldehyde analogs. As shown in Fig. 8, the four aldehyde analogs did not inhibit the degradation of the substrate at a $5-\mu \mathrm{M}$ concentration, while a much lower concentration of the proteasome inhibitor PS-341 (10 nM; a positive control) inhibited proteasome activity by $63 \%$, indicating that the apoptotic and anti-proliferative activity of our compounds was not initiated by this enzyme.

\section{Discussion}

We examined the structure-anticancer activity relationship of a series of novel aldehyde calpain inhibitors. The results of our study suggest that calpain is a promising target for development of anticancer agents. Specifically, compound 1, an analog with a five-membered heterocyclic ring at $\mathrm{P} 2$ demonstrated potent enzyme inhibitory activity and effective apoptosis-inducing activity.

Previous enzyme inhibition studies showed that the aldehyde analogs with phenylalanine at P1, arylsulfonyl group at P3 and cyclic group at P2 exhibit a range of inhibitory potency for $\mu$-calpain, with $\mathrm{Ki}$ values ranging from 0.07 to $0.54 \mu \mathrm{M}(24)$. We chose the most active analogs for further structure-activity studies. Our results indicate that the P2 position is important for both enzyme inhibition and anticancer effects. Among these analogs, those incorporating a fivemembered cyclic group at P2 (i.e., compounds 1 and 4) demonstrated the most potent $\mu$-calpain inhibitory activity, with diminished potency observed for the compounds incorporating a four or six-membered ring. Compound 5 with a $\mathrm{P}_{2}$ leucine residue was the most potent $\mu$-calpain inhibitor of the series but it was not the most effective anticancer agent in terms of its $\mathrm{IC}_{50}$ value. Although $\mathrm{Ki}$ values as determined in cell free system evaluate the intrinsic inhibitory potency of compounds for proteolytic activity, drug effects in whole cell systems are potentially confounded by factors including drug stability, cellular penetration, and/or non-specific binding, and may have contributed to the lesser anticancer activity of those latter compounds.

Tumor progression and carcinogenesis are often associated with gene or protein upregulation or downregulation. In order to investigate the possibility that calpain expression was related to the observed drug responses in cancer cells, we measured the mRNA and protein expression levels of two calpain isoforms, $\mu$ and $\mathrm{m}$, in these four cancer cell lines. Previous immunofluorescence studies suggested that leukemia cells express high levels of calpain, whereas some solid tumor cell lines, PC-3 and HeLa, express low levels of calpain (13). Our data provide contradictory results with high protein and mRNA levels of calpain in the PC-3 cell line compared to leukemia cell lines by real-time RT-PCR and Western blotting. More specifically, m-calpain protein expression varies in the four cancer cell lines, with 2-fold higher expression levels in the PC-3 cell line than in the HeLa cell line and undetectable levels in leukemia cell lines. $\mu$-calpain expression levels were similar among them. It was reported that occurrence of m-calpain in human peripheral blood lymphocyte/monocyte fraction and lymph node dropped below detectable levels in some T- and B-cells $(28,29)$ and the presence of m-calpain in some T- or B-cell lines was related to HTLV-1 infection (28), which parallels our results.

During the process of apoptosis, cells undergo sequential morphological and biological changes including PS externalization, plasma membrane blebbing, cleavage of internucleosomal DNA into multiples of $180 \mathrm{bp}$ fragments, and caspase- 3 activation. To fully characterize calpain inhibitor-induced apoptosis, several end-points of apoptosis were used: PS externalization, DNA fragmentation, caspase- 3 activation, and sub-G1 fraction of DNA content. We observed consistent results using all of these detection methods.

Although the compounds exhibited similar drug effects in the leukemia cells and the solid tumor cells, their apoptotic behaviors were significantly different and were inversely related to their calpain expression levels. Calpain inhibitors do not trigger apoptosis in PC-3 cells, which highly express $\mathrm{m}$-calpain, while leukemia cell lines with undetectable levels of m-calpain were more susceptible to undergo apoptosis in response to calpain inhibition. The extent of apoptosis in HeLa cells was moderate under identical conditions. With 24-h treatment, apoptosis induced by the compounds occurred in a dose-dependent manner in Jurkat and Daudi cells, as determined by Annexin-V FITC assay and DNA fragmentation assay. In leukemia cell types, the potency and efficacy of 
the apoptotic effects of the four compounds correlated to their $\mathrm{IC}_{50} \mathrm{~s}$. Compound 1 was the most potent, followed by compounds 2, 3 and 4. Our results indicate that the contributions of calpain inhibition to anticancer effects are cell-type dependent. Although similar $\mathrm{IC}_{50} \mathrm{~s}$ are obtained in response to compound 1 in all the cell lines, inhibition of calpain triggered a large percentage of cells to undergo apoptosis in leukemia/ lymphoma cell lines, and only marginal apoptosis in PC-3 cells, suggesting that these compounds showed cytostatic and not cytotoxic activity in PC-3 cells.

The involvement of calpain in controlling the cell cycle at multiple points has been established (7,30-33). While some studies suggested that calpain is involved in regulating the G1 checkpoint by targeting the tumor-suppressor protein $\mathrm{p} 53$ (31), cyclin D1 (30) and other proteins (34), calpain was first reported to be involved in mitosis by promoting transition from metaphase to anaphase (33). Our results are consistent with the previous finding that calpain is involved in $\mathrm{G} 2 / \mathrm{M}$ phase. One of the possible substrates is c-Mos, which functions as a cytostatic factor (CSF) and is degraded by calpain at a specific site during fertilization of Xenopus (7). Another possible substrate could be $\mathrm{p} 53$, which is required to sustain G2 arrest after DNA damage $(35,36)$. Inhibition of calpain activity by compound 1 may stabilize p53 protein expression and arrest cells in the G2 phase. Nevertheless, despite their mutated p53 status in Jurkat and p53 null status in PC-3 (1), they are also arrested and delayed in G2-M progression, suggesting that these effects were mediated via a p53independent mechanism.

These results indicate that aldehyde calpain inhibitors exhibit their anticancer effects via an induction of G2/M arrest and apoptotic cell death that involves caspase-3 activation. Similarly, G2/M phase perturbation was a dominant factor for the antiproliferative activities of the calpain inhibitors in solid tumor cell lines.

Furthermore, the specificity of these calpain inhibitors was examined. The compounds did not inhibit $20 \mathrm{~S}$ proteasome enzyme activities, ruling out any contribution from proteasome inhibition to the observed drug effects. Our results indicate that the cytostatic/cytotoxic effects induced by aldehyde calpain inhibitors were specific to calpain inhibition. Not only as anticancer agents, the series of aldehyde compounds disclosed here also offer biomedical tools for differentiating the cellular roles of calpain and $20 \mathrm{~S}$ proteasome in various pathophysiological processes. Among them, compound 1 is both a potent inhibitor of $\mu$-calpain and an effective anticancer agent. Moreover, compound 1 is more potent and specific to calpain than calpain inhibitor I and II. Hence, compound 1 is recognized as a lead compound for further study and modification.

In conclusion, the results of the present study not only support the idea of calpain as a novel target for the treatment of a variety of cancer diseases, especially leukemia/lymphoma, but also highlight compound 1 as a lead compound for future development and pharmacologic study.

\section{Acknowledgements}

This work was supported by a grant from the NIH (1R21CA104982-01).

\section{References}

1. An WG, Hwang SG, Trepel JB and Blagosklonny MV: Protease inhibitor-induced apoptosis: accumulation of wt p53, p21WAF1/ CIP1, and induction of apoptosis are independent markers of proteasome inhibition. Leukemia 14: 1276-1283, 2000.

2. Adams J, Palombella VJ, Sausville EA, Johnson J, Destree A, Lazarus DD, Maas J, Pien CS, Prakash S and Elliott PJ: Proteasome inhibitors: a novel class of potent and effective antitumor agents. Cancer Res 59: 2615-2622, 1999.

3. O'Connor OA: The emerging role of bortezomib in the treatment of indolent non-Hodgkin's and mantle cell lymphomas. Curr Treat Options Oncol 5: 269-281, 2004.

4. Kishimoto A, Kajikawa N, Shiota M and Nishizuka Y: Proteolytic activation of calcium-activated, phospholipiddependent protein kinase by calcium-dependent neutral protease. J Biol Chem 258: 1156-1164, 1983.

5. Frangioni JV, Oda A, Smith M, Salzman EW and Neel BG: Calpain-catalyzed cleavage and subcellular relocation of protein phosphotyrosine phosphatase 1B (PTP-1B) in human platelets. EMBO J 12: 4843-4856, 1993.

6. Altznauer F, Conus S, Cavalli A, Folkers G and Simon HU: Calpain-1 regulates Bax and subsequent Smac-dependent caspase-3 activation in neutrophil apoptosis. J Biol Chem 279: 5947-5957, 2004.

7. Watanabe N, Vande Woude GF, Ikawa Y and Sagata N: Specific proteolysis of the c-mos proto-oncogene product by calpain on fertilization of Xenopus eggs. Nature 342: 505-511, 1989.

8. Nixon RA: Fodrin degradation by calcium-activated neutral proteinase (CANP) in retinal ganglion cell neurons and optic glia: preferential localization of CANP activities in neurons. J Neurosci 6: 1264-1271, 1986.

9. Roberts-Lewis JM, Savage MJ, Marcy VR, Pinsker LR and Siman R: Immunolocalization of calpain I-mediated spectrin degradation to vulnerable neurons in the ischemic gerbil brain. $\mathrm{J}$ Neurosci 14: 3934-3944, 1994.

10. Hirai S, Kawasaki H, Yaniv M and Suzuki K: Degradation of transcription factors, c-Jun and c-Fos, by calpain. FEBS Lett 287: 57-61, 1991.

11. Han Y, Weinman S, Boldogh I, Walker RK and Brasier AR: Tumor necrosis factor-alpha-inducible IkappaBalpha proteolysis mediated by cytosolic m-calpain. A mechanism parallel to the ubiquitin-proteasome pathway for nuclear factor-kappab activation. J Biol Chem 274: 787-794, 1999.

12. Lu Q and Mellgren RL: Calpain inhibitors and serine protease inhibitors can produce apoptosis in HL-60 cells. Arch Biochem Biophys 334: 175-181, 1996.

13. Zhu DM and Uckun FM: Calpain inhibitor II induces caspasedependent apoptosis in human acute lymphoblastic leukemia and non-Hodgkin's lymphoma cells as well as some solid tumor cells. Clin Cancer Res 6: 2456-2463, 2000.

14. Zhu W, Murtha PE and Young CY: Calpain inhibitor-induced apoptosis in human prostate adenocarcinoma cells. Biochem Biophys Res Commun 214: 1130-1137, 1995.

15. Atencio IA, Ramachandra M, Shabram P and Demers GW: Calpain inhibitor 1 activates p53-dependent apoptosis in tumor cell lines. Cell Growth Differ 11: 247-253, 2000.

16. Satish L, Blair HC, Glading A and Wells A: Interferon-inducible protein 9 (CXCL11)-induced cell motility in keratinocytes requires calcium flux-dependent activation of mu-calpain. Mol Cell Biol 25: 1922-1941, 2005.

17. Carragher NO and Frame MC: Calpain: a role in cell transformation and migration. Int J Biochem Cell Biol 34: 1539-1543, 2002.

18. Li G and Iyengar R: Calpain as an effector of the Gq signaling pathway for inhibition of Wnt/beta-catenin-regulated cell proliferation. Proc Natl Acad Sci USA 99: 13254-13259, 2002.

19. Xu Y and Mellgren RL: Calpain inhibition decreases the growth rate of mammalian cell colonies. J Biol Chem 277: 21474-21479, 2002.

20. Rios-Doria J, Kuefer R, Ethier SP and Day ML: Cleavage of beta-catenin by calpain in prostate and mammary tumor cells. Cancer Res 64: 7237-7240, 2004.

21. Lakshmikuttyamma A, Selvakumar P, Kanthan R, Kanthan SC and Sharma RK: Overexpression of $\mathrm{m}$-calpain in human colorectal adenocarcinomas. Cancer Epidemiol Biomarkers Prev 13: 1604-1609, 2004.

22. Shinohara K, Tomioka M, Nakano H, Tone S, Ito H and Kawashima S: Apoptosis induction resulting from proteasome inhibition. Biochem J 317: 385-388, 1996. 
23. Squier MK, Miller AC, Malkinson AM and Cohen JJ: Calpain activation in apoptosis. J Cell Physiol 159: 229-237, 1994.

24. Donkor IO, Korukonda R, Huang TL and LeCour L Jr: Peptidyl aldehyde inhibitors of calpain incorporating P2-proline mimetics. Bioorg Med Chem Lett 13: 783-784, 2003.

25. Schmittgen TD: Real-time quantitative PCR. Methods 25: 383-385, 2001.

26. Herrmann M, Lorenz HM, Voll R, Grunke M, Woith W and Kalden JR: A rapid and simple method for the isolation of apoptotic DNA fragments. Nucleic Acids Res 22: 5506-5507, 1994.

27. Stein RL, Melandri F and Dick L: Kinetic characterization of the chymotryptic activity of the $20 \mathrm{~S}$ proteasome. Biochemistry 35: 3899-3908, 1996.

28. Adachi Y, Kitahara-Ozawa A, Sugamura K, Lee WJ, Yodoi J, Maki M, Murachi T and Hatanaka M: Expression of calpain II gene in human hematopoietic system cells infected with human T-cell leukemia virus type I. J Biol Chem 267: 19373-19378, 1992.

29. Farkas A, Tompa P and Friedrich P: Revisiting ubiquity and tissue specificity of human calpains. Biol Chem 384: 945-949, 2003.
30. Choi YH, Lee SJ, Nguyen P, Jang JS, Lee J, Wu ML, Takano E, Maki M, Henkart PA and Trepel JB: Regulation of cyclin D1 by calpain protease. J Biol Chem 272: 28479-28484, 1997.

31. Kubbutat MH and Vousden KH: Proteolytic cleavage of human p53 by calpain: a potential regulator of protein stability. Mol Cell Biol 17: 460-468, 1997

32. Janossy J, Ubezio P, Apati A, Magocsi M, Tompa P and Friedrich P: Calpain as a multi-site regulator of cell cycle. Biochem Pharmacol 67: 1513-1521, 2004.

33. Schollmeyer JE: Calpain II involvement in mitosis. Science 240: 911-913, 1988

34. Patel YM and Lane MD: Mitotic clonal expansion during preadipocyte differentiation: calpain-mediated turnover of p27. J Biol Chem 275: 17653-17660, 2000.

35. Bunz F, Dutriaux A, Lengauer C, Waldman T, Zhou S, Brown JP, Sedivy JM, Kinzler KW and Vogelstein B: Requirement for p53 and p21 to sustain G2 arrest after DNA damage. Science 282: 1497-1501, 1998.

36. Ando T, Kawabe T, Ohara H, Ducommun B, Itoh M and Okamoto T: Involvement of the interaction between p21 and proliferating cell nuclear antigen for the maintenance of $\mathrm{G} 2 / \mathrm{M}$ arrest after DNA damage. J Biol Chem 276: 42971-42977, 2001. 